\title{
Drug derived radicals: mediators of the side effects of anti-inflammatory drugs?
}

\author{
Barry Halliwell, Patricia J Evans, Harparkash Kaur, S Chirico
}

\section{Reactive oxygen species in rheumatoid arthritis}

It is now generally accepted that oxygen free radicals and other reactive oxygen species play some part in the pathology of inflammatory joint disease, though whether this is a major or minor part remains to be established. ${ }^{1}$ A radical is any species containing one or more unpaired electrons (denoted by a superscript dot, ${ }^{\bullet}$ ). Examples are the superoxide radical $\left(\mathrm{O}_{2}^{-}\right)$and hydroxyl radical $(\mathrm{OH} \cdot)$. The term reactive oxygen species is a broader term that includes not only $\mathrm{O}_{2}^{-}$and $\mathrm{OH}^{-}$but also certain nonradical oxygen derived species, such as hydrogen peroxide $\left(\mathrm{H}_{2} \mathrm{O}_{2}\right)$ and hypochlorous acid (HOCl), which are potentially, damaging.) Increased formation of reactive oxygen species is probably a generalised response to tissue injury, as may be the increased synthesis of other 'injury mediators' such as prostaglandins, leukotrienes, interleukins, and tumour necrosis factors. ${ }^{12}$ There is therefore nothing special in showing increased activity of reactive oxygen species in any human disease: it is almost to be expected. ${ }^{2}$ What needs to be done (as for any putatively important injury mediator) is to show that reactive oxygen species are important contributors to disease activity (table 1). This has been exceptionally difficult because reactive oxygen species are hard to measure, but fortunately new methods are becoming available. $^{1}$

\section{Sources of reactive oxygen species in} rheumatoid arthritis

Synovial fluid neutrophils, and macrophages in the pannus, probably generate some $\mathrm{O}_{2}^{-}$and $\mathrm{H}_{2} \mathrm{O}_{2}$ in the inflamed rheumatoid joint. ${ }^{3}$ In the

Pulmonary Medicine, UC Davis Medical Center, $4301 \times$ Street, Sacramento, CA 95817 , USA B Halliwell

Biomedical Sciences, King's College, Chelsea Campus, Manresa Road, London SW3 6LX, United Kingdom P J Evans H Kaur

S Chirico

Correspondence to: Dr Halliwell.

Accepted for publication 15 June 1992
Table 1 Some of the basic criteria that must be satisfied before implicating any agent as an important mediator of tissue injury in human disease

1 The agent is always present at the site of injury

2 Direct application of the agent to the tissue at concentrations within the range found in vivo reproduces most or all of the injurious effects

3 Removing the agent or inhibiting its formation decreases the injury to an extent approximately proportional to the degree of removal of the agent, or inhibition of its formation

The problems with free radicals: (1) and (3) obviously rely on accurate assay methods. Free radicals are difficult to measure: it is rarely clear what percentage of radicals formed are actually trapped when a trapping method is used and 'end products' of free radical damage are rapidly removed by excretion from the body or by metabolism (or both). Molecular excretion from the body or by metabolism (or both). Molecular targets of free radical markedly as a result of changes in radical concentration or cell measured. damage are numerous and their relative importance can change presence of 'catalytic' iron ions, which often exist in synovial fluid, ${ }^{4} \mathrm{O}_{2}^{-}$and $\mathrm{H}_{2} \mathrm{O}_{2}$ lead to the formation of highly reactive $\mathrm{OH}^{*}$ which can attack and damage lipids, carbohydrates, DNA, and proteins. ${ }^{5}$ Reaction of $\mathrm{H}_{2} \mathrm{O}_{2}$ with haemoglobin, liberated as a result of traumatic microbleeding in the joint, ${ }^{6}$ can generate oxohaem species and associated globin radicals that can oxidise many biological materials, including lipids. ${ }^{78}$ Eventually, if the $\mathrm{H}_{2} \mathrm{O}_{2}$ is in excess over the haemoglobin, the haem ring falls apart and 'free' iron is released in a form that can catalyse $\mathrm{OH}^{\bullet}$ production. ${ }^{9}$ The pannus overgrowing the cartilage contains many macrophages, presumably secreting $\mathrm{O}_{2}^{-}, \mathrm{H}_{2} \mathrm{O}_{2}$, eicosanoids, interleukin 1 , and the free radical nitric oxide, $\mathrm{NO}^{\circ}$. Under certain circumstances, ${ }^{10}$ $\mathrm{OH} \cdot$ might be produced by the reaction of $\mathrm{NO}^{\bullet}$ with $\mathrm{O}_{2}^{-}$

$$
\begin{aligned}
& \mathrm{NO}^{\bullet}+\mathrm{O}_{2}^{-} \rightarrow \mathrm{ONOO}^{-} \\
& \mathrm{ONOO}^{-}+\mathrm{H}^{+} \rightarrow \mathrm{ONOOH} \rightarrow \mathrm{NO}_{2}^{\bullet}+\mathrm{OH}^{\bullet}
\end{aligned}
$$

It has also been proposed ${ }^{11} 12$ that the inflamed rheumatoid joint undergoes repeated cycles of hypoxia-reperfusion during movement; this may result in the generation of reactive oxygen species by several mechanisms, including oxidation of hypoxanthine and xanthine by the enzyme xanthine oxidase. ${ }^{12}$

Neutrophils contain myeloperoxidase, an enzyme which uses $\mathrm{H}_{2} \mathrm{O}_{2}$ to oxidise $\mathrm{Cl}^{-}$ions into hypochlorous acid ${ }^{13}$

$$
\mathrm{H}_{2} \mathrm{O}_{2}+\mathrm{Cl}^{-}+\mathrm{H}^{+} \rightarrow \mathrm{H}_{2} \mathrm{O}+\mathrm{HOCl}
$$

Hypochlorous acid is highly reactive but more selective as an oxidant than is $\mathrm{OH}^{\bullet}$ : it reacts quickly with methionine and with protein - SH groups, for example. ${ }^{13}$ Myeloperoxidase has many of the properties of a 'typical' peroxidase enzyme: it can oxidise a wide range of substrates in the presence of $\mathrm{H}_{2} \mathrm{O}_{2}$. Such peroxidase mediated oxidations almost always ${ }^{14}$ proceed by free radical mechanisms in which the substrate $\left(\mathrm{SH}_{2}\right)$ is oxidised to a free radical $\left(\mathrm{SH}^{\bullet}\right)$

Peroxidase(III) $+\mathrm{H}_{2} \mathrm{O}_{2} \rightarrow$ peroxidase $(\mathrm{V})$

Peroxidase $(\mathrm{V})+\mathrm{SH}_{2} \rightarrow \mathrm{SH}^{\bullet}+\mathrm{H}^{\dagger}+$ peroxidase (IV)

Peroxidase (IV) $+\mathrm{SH}_{2} \longrightarrow \mathrm{SH}^{\bullet}+\mathrm{H}^{\prime}+$ peroxidase (III)

The Roman numerals represent the normal oxidation state of the iron in the peroxidase haem ring. Hydrogen peroxide oxidises the resting enzyme ( $\mathrm{Fe}(\mathrm{III})$ ) to a nominal $\mathrm{Fe}(\mathrm{V})$ state, probably an $\mathrm{Fe}(\mathrm{IV})$ state plus an amino 
acid radical. The enzyme returns to $\mathrm{Fe}$ (III) in two one-electron steps, in each of which a substrate is oxidised by the removal of one electron, so generating the substrate radical, SH•.

Attempts to measure reactive oxygen species in rheumatoid arthritis

This research group and others have spent considerable time developing 'markers' of oxidative damage and 'traps' for reactive oxygen species and applying them to patients with rheumatoid arthritis. ${ }^{1-11} 14$ 15a Experience over several years has shown that interpatient variation is enormous. For example, synovial fluid from one patient may show clear evidence of $\mathrm{OH} \cdot$ generation (using phenylalanine or salicylate as 'detector molecules') ${ }^{15 a}$ or of exercise induced increases in oxidative lipid and protein damage (presumably due to hypoxia-reperfusion events $\left.{ }^{11}\right)$. A patient with an identical degree of disease activity (as measured by clinical or laboratory parameters) may show none of these. One of the factors influencing such discrepancies may be the nature of the treatment regimen. Anti-inflammatory drugs are often proposed to decrease free radical production, but they might often enhance it instead.

\section{Anti-inflammatory drugs and oxidative damage}

All drugs used in the treatment of rheumatoid arthritis are capable of scavenging $\mathrm{OH}^{-}$in vitro, ${ }^{16}$ as do most other molecules. ${ }^{14}$ Apart from the special case of salicylate, however, drug concentrations in vivo (e.g. table 2; Baggot et $a l^{17}$ ) are probably too low to scavenge $\mathrm{OH}^{\bullet}$. As almost everything reacts quickly with $\mathrm{OH}^{\bullet}$, all that matters is concentration-a drug must be present at high concentrations to compete with biological molecules for any $\mathrm{OH} \cdot$ generated. Even in simple in vitro radical generating systems, $\mathrm{OH}^{\bullet}$ scavengers need to be present at millimolar concentrations to be effective. Similar conclusions apply to $\mathrm{HOCl}$. Although $\mathrm{HOCl}$ can react with most drugs in vitro, scavenging of $\mathrm{HOCl}$ in vivo is feasible only in a few instances, such as penicillamine, gold thiols

Table 2 Actual concentrations of anti-inflammatory drugs found in human body fluids

\begin{tabular}{lll}
\hline Drug & $\begin{array}{l}\text { Daily dose } \\
\text { often used }(\mathrm{g})\end{array}$ & $\begin{array}{l}\text { Peak plasma } \\
\text { concentration } \\
(\text { mmol/l) })\end{array}$ \\
\hline Sulphasalazine & $3-4$ & $0 \cdot 05$ \\
Methotrexate & $\approx 0 \cdot 002$ & $0 \cdot 0006$ \\
Sulindac & $0 \cdot 3-0 \cdot 4$ & $0 \cdot 02$ \\
Indomethacin & $0 \cdot 15-0 \cdot 2$ & $0 \cdot 02$ \\
Naproxen & $0 \cdot 5-1 \cdot 0$ & $0 \cdot 4$ \\
Salicylic acid & $5-8$ & $2 \cdot 0$ \\
Ibuprofen & $1-3$ & $0 \cdot 4$ \\
Mefenamic acid & $1-2$ & $0 \cdot 08$ \\
Aspirin & $5-8$ & $2 \cdot 0$ \\
Piroxicam & $0 \cdot 02$ & $($ as salicylate $)$ \\
Phenylbutazone & $0 \cdot 6$ & $0 \cdot 02$ \\
Penicillamine & $1 \cdot 5$ & $0 \cdot 5$ \\
Hydroxychloroquine & $0 \cdot 4$ & $0 \cdot 2$ \\
\end{tabular}

The daily doses and peak concentrations are approximate: the 'free' drug concentration may be lower because of protein binding. In rheumatoid arthritis there is increased permeability of the synovial membrane, so it is likely that synovial fluid drug concentrations are of the same order of magnitude as those in the plasma. Data from Baggot et al. ${ }^{17}$ (the thiol is the part active in scavenging $\mathrm{HOCl}$ ), and phenylbutazone. ${ }^{18}$ Some drugs may suppress phagocyte function and so inhibit the generation of reactive oxygen species: this ability is widely claimed on the basis of experiments in vitro (often using inappropriately high drug concentrations) but has rarely been established in vivo.

The reaction of drugs with reactive oxygen species is not necessarily a good thing. For example, oxidation of penicillamine or of phenylbutazone in vitro can generate damaging products; these are often drug derived free radicals. For example, $\alpha_{1}$ antiproteinase (the major inhibitor of serine proteases such as elastase in human body fluids) can be inactivated, apparently by reactive oxygen species mediated oxidation, in the inflamed rheumatoid joint. ${ }^{19}$ Penicillamine and phenylbutazone could accelerate this inactivation, because free radicals derived from their oxidation can themselves inactivate $\alpha_{1}$ antiproteinase. ${ }^{20} 20 \mathrm{a}$

\section{Generation of drug derived radicals}

In a few instances drug derived radicals might be produced by direct reaction of drugs with reactive oxygen species. ${ }^{18} 2020$ More often, however, they might arise because many drugs can be oxidised into radicals by myeloperoxidase, which has (as discussed earlier) a broad substrate specificity (equations 3-5)..$^{202}{ }^{21}$ Diclofenac $^{22}$ may be one example. Oxidation could be catalysed by myeloperoxidase within phagocytes, or by enzymes released from activated phagocytes. Mixtures of haemoglobin and $\mathrm{H}_{2} \mathrm{O}_{2}$ can also oxidise many drugs, including phenylbutazone. $^{20 a}$ Hence a scenario can be envisaged in which a drug might suppress certain mediators of inflammation (for example, non-steroidal anti-inflammatory drugs (NSAIDs) inhibiting cyclo-oxygenase) but simultaneously aggravate oxidative damage. Hence it is no surprise that there is, as yet, no completely effective, safe drug for the treatment of rheumatoid arthritis.

If these ideas are correct, then other areas of high peroxidase activity in the human body might be expected to be sensitive to damage by drug induced free radical reactions, provided that $\mathrm{H}_{2} \mathrm{O}_{2}$ can be generated. Indeed, bone marrow (which has high peroxidase activity due to myeloperoxidase and eosinophil peroxidase enzymes) appears to be especially sensitive to drugs and toxins that can easily generate free radicals. ${ }^{212324} \mathrm{~A}$ peroxidase has been reported to be present in the stomach of rats and mice. ${ }^{25}$ If such a peroxidase is also present in the human stomach, and $\mathrm{H}_{2} \mathrm{O}_{2}$ was generated there in vivo, then drugs might also be oxidised at this site. For example, the gastric toxicity of NSAIDs might include not only the inhibition of cyclooxygenase, but also drug derived free radicals generated in the stomach. Several workers have presented evidence consistent with the view that free radicals play a part in indomethacin induced gastric damage in animal model systems. ${ }^{26} 27$

Can these side effects be decreased?

A large number of damaging free radicals, 
including drug derived radicals, ${ }^{20 a} 232829$ can be scavenged by ascorbic acid (vitamin $\mathrm{C}$ ). The resulting ascorbate radical is poorly reactive and may disappear largely by self reaction, i.e.

2 ascorbate radicals $\rightarrow$ ascorbate + semidehydroascorbate

Ascorbic acid may also act as a preferred substrate for oxidation by haem protein- $\mathrm{H}_{2} \mathrm{O}_{2}$ mixtures, preventing them from oxidising other molecules into damaging free radicals. ${ }^{8}$

The concentrations of total ascorbate and the ascorbate to dehydroascorbate concentration ratio are markedly subnormal in patients with active rheumatoid arthritis. ${ }^{30}$ Giving supplemental ascorbate to such patients does not appear to diminish their disease activity (Blake D $R$, personal communication). It would be interesting, however, if ascorbic acid were able to minimise the occurrence of drug induced side effects.

We thank the Arthritis and Rheumatism Council for research support.

1 Halliwell B, Gutteridge J M C, Cross C E. Free radicals, antioxidants and human disease: where are we now? $\mathcal{F ~} \mathrm{Lab}$ Clin Med 1992; 6: 598-620.

2 Halliwell B, Gutteridge J M C. Lipid peroxidation, oxygen radicals, cell damage and antioxidant therapy. Lancet 1984 ; i: $1396-8$.

3 Newcombe H L, Bucknall R C, Edwards S W. Neutrophils isolated from the synovial fluid of patients with rheumatoid arthritis: priming and activation in vivo. Ann Rheum Dis 1991; 50: $147-53$.

4 Gutteridge J M C. Bleomycin-detectable iron in knee-joint synovial fluid from arthritic patients and its relationship to synovial fluid from arthritic patients and its relationship to
the extracellular antioxidant activities of caeruloplasmin, the extracellular antioxidant activities of caeruloplasmin,
transferrin and lactoferrin. Biochem $\mathcal{F} 1987 ; 245: 415-21$.

5 Von Sonntag C. The Chemical Basis of Radiation Biology. London: Taylor \& Francis, 1987.

6 Blake D R, Hall N D, Bacon P A, Dieppe P A, Halliwell B, Gutteridge J M C. The importance of iron in rheumatoid disease. Lancet 1981; ii: $1142-4$.

7 Puppo A, Halliwell B. Formation of hydroxyl radicals from hydrogen peroxide in the presence of iron. Is haemoglobin a biological Fenton catalyst? Biochem $\mathcal{F}$ 1986; 249: 185-90.

8 Rice-Evans C, Okunade G, Khan R. The suppression of iron release from activated myoglobin by physiological electron donors and by desferrioxamine. Free Radic Res Commun 1989; 7: 45-54.

9 Gutteridge J M C. Iron promoters of the Fenton reaction and lipid peroxidation can be released from haemoglobin by lipid peroxidation can be released from
peroxides. FEBS Lett 1986; 201: 291-5.

10 Beckman J S, Beckman T W, Chen J, Marshall P A, Freeman B A. Apparent hydroxyl radical production by peroxynitrite: implications for endothelial injury from nitric oxide and superoxide. Proc Natl Acad Sci USA 1990; 87: 1620-4.

11 Merry P, Grootveld M, Lunec J, Blake D R. Oxidative damage to lipids within the inflamed human joint provides evidence of radical-mediated hypoxic-reperfusion injury. Am 7 Clin Nutr 1991; 56: 362S-9S.

12 Allan R E, Outhwaite J, Morris C J, Blake D R. Xanthine oxidoreductase is present in human synovium. Ann Rheum Dis 1987; 46: 843-5.

13 Weiss S J. Tissue destruction by neutrophils. $N$ Engl f Med 1989; 320: 365-76.

14 Halliwell B, Gutteridge J M C. Free Radicals in Biology and Medicine. 2nd ed. Oxford: Oxford University Press, 1989.

15 Humad S, Zarling E, Clapper M, Skosey J K. Breath pentan excretion as marker of disease activity in rheumatoid arthritis. Free Radic Res Commun 1988; 5: 101-6.

15a Halliwell B, Chirico S, Kaur H, Aruoma O I, Grootveld M, Blake D R. Application of new assays for measuring free radical production to human rheumatoid patients. In: Davies K J A, ed. Oxidative damage and repair. Oxford: Pergamon Press, 1992: 846-55.

16 Aruoma O I, Halliwell B. The iron-binding and hydroxyl radical scavenging action of anti-inflammatory drugs. radical scavenging action of
Xenobiotica 1988; 18: 459-70.

17 Baggot J E, Morgan S L, Ha T, Vaughan W H, Hine R J. Inhibition of folate-dependent enzymes by non-steroidal anti-inflammatory drugs. Biochem $\mathcal{F}$ 1992; 282: 197-202.

18 Wasil M, Halliwell B, Moorhouse C P, Hutchison D C S Baum $H$. Biologically significant scavenging of the myeloperoxidase-derived oxidant hypochlorous acid by some anti-inflammatory drugs. Biochem Pharmacol 1987; 36 : 3847-50.

19 Chidwick K, Winyard P G, Zhang Z, Farrell A J, Blake D R. Inactivation of the elastase inhibitory activity of $\alpha_{1}$ antitrypsin in fresh samples of synovial fluid from patients with trypsin in fresh samples of synovial fluid from patients

20 Aruoma O I, Halliwell B, Butler J, Hoey B M. Apparent inactivation of $\alpha_{1}$-antiproteinase by sulphur-containing radicals derived f

20a Evans P J, Cecchini R, Halliwell B. Oxidative damage to lipids and $\alpha_{1}$-antiproteinase by phenylbutazone in the presence of haem proteins. Protection by ascorbic acid. Biochem Pharmacol. In press.

21 Uetrecht J P. Drug metabolism by leukocytes, its role in drug-induced lupus and other idiosyncratic drug reactions. CRC Crit Rev Toxicol 1990; 20: 213-35.

22 Zuurbier K W M, Bakkenist A R J, Fokkens R H, Nibbering N M N, Wever R, Muijsers A O. Interaction of myeloperoxidase with diclofenac. Biochem Pharmacol 1990; 40: 1801-8.

23 Fischer V, Haar J A, Greiner L, Lloyd R V, Mason R P. Possible role of free radical formation in clozapine (clozaril)Possible role of free radical formation in clozapine (clozaril)-
induced agranulocytosis. Mol Pharmacol 1991; 40: 846-53.

24 Subrahmanyam V V, Ross D, Eastmond D A, Smith M T. Potential role of free radicals in benzene-induced myelotoxicity and leukemia. Free Radic Biol Med 1991; 11. toxicity

25 Banerjee R K. Non-steroidal anti-inflammatory drugs inhibit gastric peroxidase activity. Biochim Biophys Acta 1990 1034: 275-80.

26 Romano M, Razandi M, Raza A, Szabo S, Ivey J. Cysteamine protects gastric epithelial cell monolayers against druginduced damage: evidence for direct cellular protection by sulphydryl compounds. Gut 1992; 33: 30-8.

27 Vaananen P M, Meddings J B, Wallace J L. Role of oxygenderived free radicals in indomethacin-induced gastric injury. Am $\mathcal{F}$ Physiol 1991; 261: G470-5.

28 Tamba $M$, O'Neill $P$. Redox reactions of thiol free radical with the antioxidants ascorbate and chlorpromazine: role in radioprotection. f Chem Soc Perkin Trans 2, 1681-5.

29 Halliwell B. How to characterize a biological antioxidant. Halliwell B. How to characterize a biologic
Free Radic Res Commun 1990; 9: 1-32.

30 Lunec J, Blake D R. The determination of dehydroascorbic acid and ascorbic acid in the serum and synovial fluid of patients with rheumatoid arthritis. Free Radic Res Commun 1986; 1: 31-9. 